aislada y ventilada, se reviste de chapa de aluminio e interiormente quedan vistas como un ligero entramado reticular. La estructura de cubierta con una escala poco doméstica se ha proyectado como un sistema modular que favorece la lectura unitaria y simultánea tanto del conjunto como del detalle. De esta manera, la presencia dominante de la estructura de cubierta consigue la sensación de ligereza subrayada por la luminosidad perimetral que produce el cerramiento traslúcido.

El cálculo de esfuerzos para las grandes dimensiones que se requerían para construir la "sombra" debía desembocar en la elección de unos perfiles que quedarían vistos en el espacio interior. Las decisiones eran conjuntas para arquitectos e ingenieros y el objetivo era común, pero abordado con distintas herramientas de proyecto y distintos medios de expresión. La cubierta metálica laminar está formada por tres bóvedas para la Villa de $22.5 \mathrm{~m}$. de luz y una bóveda aislada para las Termas de $25 \mathrm{~m}$. de luz. Las bóvedas se construyen con rombos de 375 $\times 250 \mathrm{~cm}$. construidos con tubos rectangulares de $200 \times 80 \times 8 \mathrm{~mm}$. existiendo 10 rombos en la dirección de la luz en la bóveda aislada y 9 rombos en las tres restantes. Apoyan perimetralmente sobre pilares HEB-200 cada 3.75 m., en los lados exteriores. Un HEB-200 une todos ellos perimetralmente a la altura de la coronación de pilares. En el centro de la Villa cuatro pilares en el patio central con luces de 22.5 m., soportan dos vigas metálicas compuestas y continuas para el apoyo central de las bóvedas que se atan transversalmente por tensores que unen dos apoyos opuestos, limitando los desplazamientos horizontales de las cabezas de los pilares y las posibles deformaciones.

Era decisiva la altura a la que se debía situar la sombra de la cubierta; lo suficientemente alta para evocar la riqueza de un gran espacio, para que quedara suspendida en el aire permitiendo la visión completa del espacio arqueológico. Pero a su vez, la cubierta no debía sobrepasar cuedar difuminada y quedar difuninada en el paisaje. Ésta se levanta a 10 metros sobre el plano de los mosaicos que el visitante contempla desde la pasarela continua horizontal elevada $1,15 \mathrm{~m}$. respecto de la cota de los mosaicos, apoyada en una red de pilarcillos que sortean los pavimentos protegidos y hacen compatible las geometrías de las estancias y del recorrido. El programa funcional se infiltra a lo largo del recorrido entre los muros romanos, sin tocarlos, pero enlazados mediante la pasarela. Noli me Tangere fue el lema de concurso de La Olmeda, no tocar la arqueología sino discurrir a su lado, construyendo ese recinto del tiempo para el que arquitectura e ingeniería se integran. En La Olmeda la forma resistente se funde con el concepto arquitectónico para pasar a formar parte esencial del mismo y construir un enmarcado estructural para los mosaicos.

La propuesta de musealización integral de un yacimiento del siglo IV en el siglo XXI no sólo tiene como objetivo proteger y contemplar los mosaicos sino transmitir la sensación de visitar una Villa Romana. Conceptualmente en la intervención en la Villa de La Olmeda, la antigüedad se confronta necesariamente con la modernidad y la arquitectura e ingeniería con la arqueología. Y quizá por este motivo arquitectura y estructura deban ser una misma cosa ante la poderosa presencia de la arqueología. El término ingenio, del que deriva el de ingeniería, como disciplina que resuelve las necesidades tecnológicas, en La Olmeda construye un espacio arquitectónico que cobija el tiempo. La estructura de la cubierta no sólo responde a criterios de estabilidad o resistencia, sino resuelve con actitud integradora la presencia de los fragmentos del pasado en un espacio contemporáneo, construyendo algo tan inmaterial como es una gran sombra.

ÁNGELA GARCÍA DE PAREDES es Doctora Arquitecta por la Universidad Politécnica de Madrid (UPM) y profesora titular del departamento de proyectos arquitectónicos de la ETSAM.

\title{
Veinte microrelatos
}

Palimpsesto editorial

Recibido 2020.04.29 ::.: Aceptado 2020.04.30

DOI: 10.5821/palimpsesto.21.9511

ABSTRACT

La paradoja de la arquitectura es también la multiplicidad de sus razones. Palimpsesto les ha prestado atención a través de sus distintas secciones, como reflejamos en el acto celebrado en la ETSAB el 17 de diciembre de 2019 con molvo de la efemeride del numero 20, con Oriol Bohígas y Federico Correa como testigos y protagonistas.

Se trata de 20 microrelatos surgidos de un crisol de aportaciones a lo largo de la trayectoria de la revista que fotografian el presente y futuro de la Escuela de Arquitectura Elena Fernández, Albert Albareda, Olga Felip, Pau Saraue, Estel Ortega, Francisco González de Canales, Eva Prats, Jorge Vidal, Carolina García, Ricardo Devesa, Stel.la Rahola, Josep Ferrando, Maria Alejandra Vilanova, Carles Crossas, Anna i Eugeni Bach, Ferran Grau, Mara Partida y Roger Such.

PALABRAS CLAVE: cátedra blanca; microrelatos; ETSAB.

Persona de contacto: alberto@penin.es

ORCID: https://orcid. org/0000-0002-5099-8644

Doctor arquitecto por la UPC

\section{Ariadna Perich}

¿Cómo ha alimentado en tu opinión tu bagaje y trayectoria cultural e intelectual a la arquitectura que desarrollas en estos momentos?

Ya hace un tiempo que entiendo la arquitectura como un hecho cultural, y la práctica profesional como un espacio de investigación continuo con una fuerte componente analítica y experimental. Con la madurez personal y profesional he ido identificando y reconociendo aquellos lugares de conocimiento que son realmente de mi interés y puedo afirmar que mi pasión por la disciplina arquitectónica se nutre y alterna con la de las prácticas artísticas y curatoriales; una formación complementaria y curiosidad permanente que creo imprescindible para la construcción de un pensamiento realmente crítico y transversal, nsabilidad y contemporaneidad a los retos que nos plantea la profesión actualmente.

\section{Jaume Prat}

Todos recordamos a Xumeu Mestre y tu escrito fue una hermosa forma de hacerlo. ¿En qué habría podido influir Xumeu en tu relación con los alumnos?

Xumeu Mestre nos hacía reír. Reírse es importante en una clase de proyectos. Podía ser muy divertido descubrir cómo nada es lo que parece a través de las perspectivas barrocas (sí, barrocas) de Mies van der perspectivas barrocas (sí, barrocas) de Mies van der Rohe, de la miradas: la de Mona Lisa persiguiénd mundo plano. La aproximación lateral al problema las relaciones entre la arquitectura y cualquier otra arte y, a través de ellas, con la vida, evidenciaban el alma curiosa de este profesor. Que nos ponía a la persona por encima de todo. Su visión antropocéntrica, pedestre, hacía que no olvidásemos a quién va dirigido lo que hacemos. Qué es lo realmente importante. Y que conseguirlo riéndonos va a hacer que la arquitectura, y nosotros a través de ella, seamos mejores.

\section{Elena Fernández}

A la luz de las relaciones epistolares que desveló tu tesis, ¿qué era más importante para los arquitectos que estudiaste: el encargo o la relación con el personaje que habitaría la casa?

Yo diría que ambos, pues las diez y seis casas estudiadas constatan que su valor arquitectónico reside en la propia formulación del encargo, una comisión que sintetiza de forma insoslayable la relación entre los dos personajes: el arquitecto y el habitante. De esta relación epistolar y directa entre los personajes involucrados se evidencia cómo el arquitecto, antes de construir la obra, tuvo que construir al habitante, estrategia necesaria para enunciar el encargo que le posibilitaría necesaria para enunciar el encargo que le pabo su "manifiesto construido".

\author{
Albert Albareda
}

¿Los métodos de cálculo contemporáneos no intuitivos, como el método de los elementos finitos, tienen incidencia en la conceptualización de la estructura como soporte espacial?

La intuición estructural es parte intrínseca e indisoluble del Arquitecto y ha jugado un papel fundamental en la historia de la Arquitectura. En la actualidad, la posibilidad de utilizar con relativa facilidad una herramienta tan poderosa como el análisis en Elementos Finitos, ha invertido muchas veces el proceso de diseño clásico estructural, relegando a la vieja intuición a ocupar injustamente un rol secundario en este proceso. Justamente por eso es ahora cuando más imprescindible es, puesto que el infinito de posibilidades sinsentido que permite una estructura diseñada por elementos finitos, debe justificarse siempre por la intuición para que funcione bien.

\section{Olga Felip}

En un trabajo en equipo como es Arquitecturia, ¿qué papel juega cada uno de vosotros si es que lo podéis distinguir?

En CF_Arquitecturia podríamos definir distintas personalidades de cada uno de nosotros, pero difícilmente roles preestablecidos en cuanto al desarrollo del proyecto. Intentamos tomar una cierta distancia, de tal modo que cada uno pueda intervenir en el momento más conveniente. Pensamos que cada proyecto tiene su autonomía y requiere de miradas y aportaciones de conocimientos en momentos que no siempre se repiten. Los proyectos en CF Arquitecturia tienen dos ritmos: por un lado, el diálogo y la conversación entre todos los miembros del equipo en los momentos clave del proyecto y por otro, un proceso lento y acumulativo en el que cada uno empieza a raíz de la reflexiones y aportaciones que ha realizado el otro.

\section{Pau Sarquella}

¿Qué relación podría existir entre la arquitectura que llamamos aquí efímera, con aquella que lo es porque no aguanta el tiempo en otros contextos culturales?

Ambas representaciones de la fugacidad arquitectónica suelen ser fruto de la manipulación, con grandes dosis de ingenio e intuición, de materialidades a las que bien sea por condiciones económicas o de proximidad se encuentran al alcance de los creadores.

Autoconstruidas en muchos casos, son generadoras de pensamiento a partir del hacer, del fabricar. Arquitecturas ligeras que entienden y dialogan con el paisaje en el que se ubican para, con un máximo respeto, desaparecer sin dejar rastro. Unas estáticas, se desmontan, y las recordamos siempre jóvenes, sin rasguños, como crisálidas paradas en el tiempo, las otras dinámicas, afectadas por el clima y su uso, envejecen hasta que se desintegran.

\section{Estel Ortega}

Has trabajado como 'curator' en multitud de exposiciones. Qué es para ti lo más sustantivo que pude plantear una exposición: ¿la obra, la personalidad del personaje o su posicionamiento ideológico?

El valor más trascendente de una exposición es, sin duda (e independientemente de que el foco esté en un autor, obra o movimiento concreto), su capacidad de construir preguntas críticas de donde puedan nacer debates paralelos con objeto de abrir brechas en valores (a menudo excesivamente) arraigados de conocimiento (social, político, económico, etc). Para darle forma, todo es válido: un divertimento o una acción aparentemente irreverente basada en la pura belleza pueden ser capaces de morder tan fuerte como los formatos más clásicos ... siempre y cuando el mensaje que se quiere lanzar, esté bien claro. 
Francisco González de Canales

¿Qué puente establecerías entre la experimentación que habrás conocido como docente en la AA y tu relación con una escuela como la de Sevilla?

La experimentación no tiene un valor por sí misma si no cuestiona relaciones fundamentales desde las que se plantea la arquitectura. La enseñanza de la arquitectura en España se ha basado a menudo en la construcción de un canon de conocimiento compartido. La Architectural Association es, sin embargo, una escuela de arquitectura anticanónica, que establece como base de conocimiento la necesidad de aceptar una pluralidad de posiciones en arquitectura. Ese mismo espíritu es exportable a cualquier escuela, en cualquier contexto.

\section{Eva Prats}

De las tres aportaciones que has hecho en la trayectoria de la revista (el edificio 111, el diálogo sobre las azoteas y la bienal de Venecia) inos quedamos con la sala Beckett! ;Cuál podría ser el argumento que liga a las tres aportaciones con este estupendo proyecto?

\section{Las tres aportaciones hablan de proyectos que} construyen comunidades.

En el edificio 111 construimos una plaza en su interior, con una fuente y tres árboles donde vecinos que vienen de diversos orígenes, economías y culturas, se encuentran casualmente y llegan a conocerse, construyendo una comunidad de la diversidad. El proyecto final de carrera unía los terrados de una El proyecto final de carrera unía los terrados de una
isla de l'Eixample para organizar unos jardines donde hacer las prácticas de la escuela de jardinería Rubió i Tudurí. El nuevo jardín en el terrado invitaba a todos los vecinos de la isla, la mayoría personas mayores que vivían solas, a pasear, mientras los estudiantes cuidaban de la vegetación. El proyecto creaba una En la sala Beckett los actores, los antiguos cooperativistas y el público comparten un edificio donde la antigua cooperativa, los años de abandon y la nueva Sala Beckett conviven. El proyecto busca extender una comunidad en el tiempo, hacer de la memoria un lugar.

\section{Jorge Vidal}

En tus grupos de proyectos de la Cátedra Blanca, siempre hacías hincapié en la construcción de atmósferas. En tu opinión, ¿cuál sería el mecanismo para trasladar este objetivo a la gran escala?

Entiendo la construcción de la atmósfera como la construcción de una narración, de una narrativa que sucede en el espacio y está en relación a personas, sitios y técnicas. Ese triedro es que el que puedes sitios y técnicas. Ese triedro es que el que puedes extrapolar a todas las escalas y ese conjunto es el Podemos decir que pasamos de las personas a las culturas, de los sitios a los paisajes, de las técnicas a la industria. Como le ocurría George Perec en su libro "Pensar/Clasificar" o en "Especies de Espacios" las preguntas se van escalando y por la tanto las relaciones entre las cosas también.

\section{Carolina García}

En tu artículo Sun and Shadow nos hablas de algunas influencias, en este caso a través de libros, que están detrás de la arquitectura que nos ha legado Josep María Sostres. ¿En la arquitectura contemporánea el recurso a las fuentes es todavía descifrable?

Descifrar los orígenes de toda arquitectura siempre será una pregunta sin una única respuesta. Sus fuentes transitan entre las páginas impresas de un libro, las imágenes que relampaguean en nuestras retinas, las sensaciones de los lugares que se visitan o la memoria de aquello que merece o no ser recordado. El proceso de creación es eterno, como eterno es el viaje que decteriono es mesa o habitación. El tiempo no importa. Tampoco mesa o habitación. El tiempo no importa. Tampoco los objetos y herramientas que en ella se reúnan.
Desde Homero, Jonathan Swift, Xavier de Maistre o Julio Cortázar, el papel es solo un pretexto para seguir pensando.

\section{Ricardo Devesa}

Nos trajiste la idea de la repetición y el cambio a través de visiones fímicas de la vida en torno a un árbol. ¿Cómo imaginas hoy la relación entre lo natural y lo artificial?
Descifrar los orígenes de toda arquitectura siempre será una pregunta sin una única respuesta. Sus fuentes transitan entre las páginas impresas de un libro, las imágenes que relampaguean en nuestras retinas, las sensaciones de los lugares que se visitan o la memoria de aquello que merece o no ser recordado. El proceso de creación es eterno, como eterno es el mesa o habitación. El tiempo no importa Tampoco mesa o habitación. El tiempo no importa. Tampoco Desde Homero, Jonathan Swift, Xavier de Maistre Desde Homero, Jonathan Swift, Xavier de Maistre o
Julio Cortázar, el papel es solo un pretexto para seguir pensando.

\section{Stella Rahola}

¿Por qué eliges la escultura como medio de expresión sobre tus ideas por encima de la arquitectura?

Siempre he entendido la arquitectura como un arte. Con el paso por la universidad suiza de Mendrisio tuve la oportunidad de tener un acercamiento humanístico mayor de la arquitectura. Ese espacio era el que me interesaba. Trabajar con Zumthor me dio unas pautas muy propias de la exploración artística. Descubrí que quería trabajar con el material, su capacidad de transformación, la construcción, tectónica, el espacio y su percepción de un modo más íntimo, más físico, directamente ligado con el que hacer manual. La escultura y la instalación me han permitido desarrollarlas con más intensidad, intimidad y con una libertad distinta. Mi práctica refleja de un modo abierto y sincero mis reflexiones y aprecio hacia la arquitectura.

\section{Josep Ferrando}

La silla que has diseñado nos ha sorprendido por su, en nuestra opinión, capacidad de sintetizar tu pensamiento arquitectónico. ¿Cómo definirías tu silla?

La silla Biennale es un espacio arquitectónico basado en la monomaterialidad, la geometría y la eficiencia. Un asiento modular y flexible realizado en un único material, cálido y confortable. Creada en madera, y fabricada industrialmente a partir de procesos artesanales, la silla aúna experiencia y eficiencia energética para concluir con un sistema flexible y personal, que da respuesta a los diversos usos de colectividad que se pueden plantear.

\section{María Alejandra Vilanova}

dentificaste distintos espacios de la ciudad de Barcelona como escenarios para el cine. ¿El espacio condiciona el relato? ¿O es más bien al contrario?

Las locaciones que cada director elige para rodar las escenas de un film tienen características espaciales que abonan y colaboran con la construcción y la composición espacial de las mismas y por lo tanto del relato. Sin embargo, estas locaciones o, la ciudad "retratada", se comporta como una actriz: tiene rasgos que la caracterizan y definen, pero es capaz mutar y construir diversos personajes según el guion requiera. De esta manera, el espacio que se reconstruye a partir de la ficción aporta sus rasgos para caracterizar la escena, pero creo que es el relato el que termina de moldear y condicionar la imagen de la ciudad de moldear
ficcionada.

\section{Carles Crosas}

Desde que ya hace 50 años el LUB instaurara e proyecto urbano en el terreno de la pedagogía urbanística como referencia en la ordenación de la ciudad, cabrí preguntarse precisamente coút la ciudad, cabria preguntarse pecisamente zcual es la vigencia hoy de este tipo de proyecto en la ciudad contemporánea?

Las locaciones que cada director elige para rodar as La aproximación al proyecto urbano propuesta por Manuel de Solà-Morales en los 80 sigue siendo una fecunda inspiración pedagógica y una guía de compromiso en nuestra práctica profesional. En un urbanismo amenazado por los clichés de la ortodoxia y los beneficios de la multipliscinariedad, el proyecto urbano de escala intermedia es un espacio de diálogo fértil entre la arquitectura y la ciudad; un proceder necesario entre los planes burocráticos holísticos y las macro-arquitecturas auto-referenciadas y una apuesta compleja por entrelazar arquitectura, programas mixtos, infraestructuras, espacios libres. Una herramienta capaz de integrar las dimensiones de lo ecosistémico y lo durable, lo táctico y lo adaptable, mejorando el hacer y rehacer de nuestras ciudades.
Anna y Eugeni Bach

Si uno de los pilares de vuestra actuación en e pabellón de Mies de Barcelona consiste en el borrado la materialidad, icrees que es posible o conveniente, imaginar, y construir, una arquitectura aparentemente despojada de materia?

Tu pregunta utiliza una palabra que contiene, implícitamente, nuestra respuesta: Cuando escribes el adverbio "aparentemente", estás tomando por sentado que la arquitectura necesita de manera inevitable la materia para ser imaginada y construida, y que el modo de oponerse a esta afirmación es jugar con las apariencias para minimizar su materialidad.

En cierto sentido, podemos estar de acuerdo. Al fin y al cabo, para "desmaterializar" el Pabellón de Barcelona utilizamos un vinilo blanco que recubriera todas sus superficies.

En definitiva, lo que hicimos, fue utilizar otro material.

\section{Ferran Grau}

En tu tesis doctoral afirmas que el realismo crítico asume un fuerte compromiso con la ciudad construida la sociedad y la disciplina arquitectónica. ¿Cómo se traduce este compromiso a la docencia?

El realismo crítico contemporáneo es deudor, entre otros, del realismo pictórico del siglo XIX, del realismo activista del Team $X$ y del realismo de del realismo activista del Team X y del realismo de Regionalismo critico. Todos ellos comparten una
actitud comprometida (de resistencia) ante corrientes arquitectónicas, culturales y socioeconómicas impuestas sin atender suficientemente a debates previos. Precisamente esta actitud que integra un conocimiento plural y en definitiva, una definición expandida del contexto (Zaera), es la base de en la que se apoya una docencia crítico realista. Una enseñanza que apuesta por el debate colectivo, la incorporación de parámetros contemporáneos, y la investigación pedagógica, como herramientas realistas al servicio de la creación de conocimiento.

\section{Mara Partida}

¿Qué es lo más sustantivo, tal vez una sola cosa, que significó para vosotros ti construir la casa de las ideas de García Lorca?

Federico García Lorca pensaba trasladarse a México semanas antes de morir. Su Fundación, con la convocatoria del concurso buscaba aquel espíritu valiente y polifacético. Si ganar el concurso fue crucial en nuestra carrera profesional, construirlo ha sido un camino largo tras 10 años y una crisis económica. Construir la casa de las ideas de Lorca, marca en nuestro hacer la ausencia de límites en arquitectura: cómo una idea potente puede llegar a hacerse realidad a través del oficio, del uso de los materiales, de la técnica, y de la resolución de retos no convencionales, la mejor traducción del espíritu del poeta.

\section{Roger Such}

En la entrevista qué le hicisteis a Le Corbusier, ¿cuál fue la respuesta que más te sorprendió? ¿Qué supuso para ti enfrentarte a este reto?

Un buen profesor se sirve casi siempre de los mismos maestros. En sus clases, ante cualquier enunciado o proyecto aparecen insistentemente, se recurre a la misma arquitectura. Hay profesores que repiten por comodidad, enseñan a través de los maestros que mejor conocen; aquellos que han estudiado previamente. Otros por responsabilidad, utilizan los que mejor trasmiten sus ideas. Pero el mejor profesor es aquel que escoge por afinidad personal, casi por devoción. Selecciona aquella arquitectura con la que el alumno experimenta la emoción de la arquitectura. Detrás de cada clase hay un profesor con un deseo, un anhelo, que no es otro que el de mimetizarse con el maestro con el que enseña.

PALIMPSESTO EDITORIAL. Carlos Ferrater, Alberto Peñín, Cecilia Obiol. 